\title{
Derleme
}

\section{Management of Cardiac Arrest in Pregnancy}

\author{
Berrin GÜNAYDIN*1, Lawrence C. TSEN**2
}

\section{ABSTRACT}

Cardiopulmonary arrest, which is seemingly uncommon with an estimated incidence of 1 in 20,000 pregnant women, can occur at any time. Therefore, clinicians should be prepared to respond immediately. Maternal resuscitation is performed with only a few minor adjustments due to the anatomic and physiologic changes of pregnancy. Anesthesiologists, obstetricians and neonatologists should work as a team to ensure appropriate treatment of both mother and newborn. This review article will address the management of cardiac arrest in pregnancy and the use of perimortem cesarean delivery.

Keywords: pregnancy, cardiac arrest, cardiopulmonary resuscitation (CPR)

\section{$\ddot{0} \mathbf{z}$}

\section{Gebelikte Kardiyak Arrest Yönetimi}

Gebelerde yaklaşık 20.000'de 1 rastlanan kardiyopulmoner arrest, nadir gibi görünse de her an olabilir. Bu nedenle klinisyenler hizla cevap vermeye hazırlıklı olmalıdır. Maternal resüsitasyon, gebeliğin anatomik ve fizyolojik değișikliklerine bağlı çok küçük ayarlamalarla gerçekleştirilir. Anesteziyologlar, obstetrisyenler ve neanatologlar hem anne hem de yenidoğan için uygun tedaviyi sağlamak için takım olarak çalışmalıdırlar. Bu derleme makale, gebelikte kardiyak arrest yönetimini ve perimortem sezaryen kullanımı sunmaktadır.

Anahtar kelimeler: gebelik, kardiyak arrest, kardiyopulmoner resüsitasyon (KPR)

\section{INTRODUCTION}

The World Health Organization (WHO) has reported an overall decline in the maternal mortality rate (MMR) from 385 to 216 per 100,000 live births (1990 to 2015). Within the United States and Turkey, based on 2015 data from the WHO, UNICEF, UNFPA, World Bank Group, and the United Nations Population Division, the MMR is 16 and 14 per 100, 000 live births, respectively ${ }^{[1]}$. Although these data are promising, cardiac arrest in pregnancy occurs more frequently than previously appreciated, and are frequently poorly managed, leading to maternal and fetal morbidity and mortality.

\footnotetext{
Alındığı tarih: 01.11.2016

Kabul tarihi: 04.11.2016

*Gazi Üniversitesi Tıp Fakültesi Amesteziyoloji Anabilim Dalı

**Harvard Üniversitesi Tıp Fakültesi, Birgham Kadın Hastanesi, Anesteziyoloji Anabilim Dalı

Yazışma adresi: Prof. Dr. Berrin Günaydın, Gazi Üniversitesi Tıp Fakültesi, Anesteziyoloji Anabilim Dalı, Beşevler 06500 Ankara e-mail: gunaydin@gazi.edu.tr

It was presented in part at the $49^{\text {th }}$ Annual Meeting of Turkish Anesthesiology and Reanimation Society (TARK 2015) in AntalyaTurkey $^{(* 2)}$ and $3^{\text {rd }}$ World Congress of Regional Anaesthesia and Pain Therapy (WCRAPT 2013) in Sydney-Australia ${ }^{\left({ }^{* 1)}\right.}$
}

A number of etiologies can result in maternal cardiac arrest. Direct causes include hemorrhage, hypertensive disorders including preeclampsia, sepsis and amniotic fluid embolus, while indirect causes include cardiac disorders, new onset infections, exacerbation of preexisting chronic diseases or psychiatric disorders ${ }^{[2]}$.

Basic and advanced life support (BLS, ALS) and resuscitation can be life saving. Maternal cardiac resuscitation should include a few important alterations to accommodate the physiological and anatomical changes of pregnancy (Figure 1). Guidelines from the American Society of Anesthesiology (ASA, 2013) and the consensus statements from the Society for Obstetric Anesthesia and Perinatology (SOAP, 2014) have assessed the available evidence on the management of cardiac arrest during pregnancy ${ }^{[3,4]}$. Since dissemination and adherence to these guidelines can be difficult, benefit to the global medical community should optimize maternal and neonatal outcomes.

In this review, we provide a brief overview of the latest evidence and guidance to improve maternal and fetal outcomes following maternal cardiac arrest. 


\title{
First Responder
}

- Activate maternal cardiac arrest team

- Document onset time of cardiac arrest

- Place the patient supine

- Start chest compressions as per BLS algorithm

- Do not delay defibrillation

- Administer ACLS resuscitation drugs in usual doses

- Use capnography to monitor CPR efficiency

- Prepare for post-cardiac arrest care

Maternal Modifications

- Establish IV access above diaphragm (can use an intraosseous infusion)

- Start IV bolus and/or infusion of fluids while assessing hypovolemia

- Discontinue IV magnesium therapy if present, and start $10 \%$ calcium chloride $10 \mathrm{~mL}$ or $10 \%$ calcium gluconate $30 \mathrm{~mL}$

- Continue CPR including positioning, defibrillation, resuscitation drugs and fluids during and after cesarean delivery

\section{Subsequent Responders}

Perform obstetric interventions

- Provide manual left uterine displacement (LUD) to reduce aortocaval compression by gravid uterus

- Remove fetal monitors (internal and external, if attached)

Obstetric anesthetic, and neonatal teams should immediately prepare for possible emergency or perimortem cesarean delivery

- Consider immediate cesarean delivery if there is no ROSC within 4 minutes of maternal cardiac arrest

Treat possible causes (BEAU-CHOPS)

\author{
Bleeding/DIC \\ Embolism:coronary/pulmonary/amniotic fluid \\ Anesthetic complications \\ Uterine atony \\ Cardiac disease (MI, ischemia/aortic dissection/cardiomyopathy) \\ Hypertension/preeclampsia/eclampsia \\ Other: hypovolemia, hypoxia, hydrogen ion (acidosis), hyper- $/$ \\ hypo-kalemia, hypothermia, toxins, tampanade (cardiac), tension \\ pneumothorax, thrombosis (coronary and pulmonary). \\ Placenta abruptio/previa \\ Sepsis
}

Figure 1. Maternal resuscitation algorithm in the event of cardiac arrest.

\section{Basic Life Support (BLS) and Calls for Help}

Immediate BLS should be started with high quality chest compressions. Meanwhile, the warning system (Code Blue at many institutions) should be immediately activated for early expert assistance including an obstetrician and neonatologist so an emergent cesarean delivery can be commenced within 4 minutes, if resuscitation has not occurred ${ }^{[5,6]}$. A defibrillator or automated external defibrillator (AED) and airway management devices should be brought to the room. Once the airway is opened, ventilation should commence with $100 \%$ oxygen, if available, or air.

\section{Chest Compressions}

Chest compressions with a depth of approximately 5 $\mathrm{cm}$ and a rate of 100 per minute should be performed with minimal interruptions and allowance of full recoil of the chest wall ${ }^{[7,8]}$. A brief ( $<10$ seconds) pause can be used for specific interventions (e.g., use of defibrillator, insertion of advanced airway); a period more than 10 seconds can decrease the chance for return of spontaneous circulation (ROSC) Compressions should be resumed immediately after defibrillation; waiting to perform a pulse check is no longer recommended ${ }^{[7-9]}$. Immediately prior to and after an endotracheal intubation, compressions should resumed; if intubation fails, 30 chest compressions followed by 2 breaths should be performed in continuous cycles at a rate of 100 compressions/min ${ }^{[8]}$. The ACLS providers responsible for chest compression should be changed every two minutes to allow effective cardiac compressions ${ }^{[8-12]}$; because hospital beds are typically not firm, a backboard can be placed un- 
der the patient, despite insufficient evidence for their use, with proper attention to avoid delays, interruptions or displacement of lines/tubes.

In the third trimester, hand placement should be in the "normal position" (i.e., with the heel of one hand in the middle of the chest on the lower half of the sternum, and the other hand on top of the first) as with non-pregnant patients; there is currently not enough evidence to support older guidance of moving the hands 2 to $3 \mathrm{~cm}$ higher on the sternum during pregnancy ${ }^{[5]}$.

Current guidelines recommend the use of capnography to confirm correct endotracheal tube placement and to assess the efficacy of chest compressions ${ }^{[8]}$. Capnography indirectly measures cardiac output in an intubated patient with stable ventilation ${ }^{[13]}$. During resuscitation, rising end-tidal $\mathrm{CO}_{2}$ levels or sustained levels above $10 \mathrm{mmHg}$ suggest adequacy of chest compressions and may be predictive of ROSC ${ }^{[14-18]}$. Use of continuous capnography if not readily available, should neither result in interruption of high-quality chest compressions nor delay perimortem delivery in the event of no ROSC.

\section{Positioning of Parturient and Left Uterine Dis- placement (LUD)}

Aortocaval compression by the enlarging uterus can occur as early as 12 to 14 weeks of gestation; this can result in increased afterload and decreased preload to the heart. These alterations are particularly present if the uterus is visible or palpable at or above the umbilicus (approximately 20 weeks of gestation) or even earlier if the gestation is associated with multiple fetuses, polyhydramnios, or other conditions ${ }^{[5,19-21]}$.

Optimal chest compressions are provided in the supine position, and use of a firm surface (e.g., a backboard) with manual left uterine displacement (LUD) ${ }^{[5,22-24]}$. Manual LUD is performed from the left side of the patient with two hands pulling the uterus leftward and upward (toward the ceiling); any downward force can compress the vena cava, and should be avoided. If left-sided LUD is not possible, it may be applied from the right side by pushing away and toward the ceiling manually ${ }^{[5]}$. Alternatively, left lateral tilt of the patient to a full 30 degrees (i.e., pelvic tilt) can be provided with a backboard or pillow, blanket or knees behind the lumbar/pelvic region, however, this position can make chest compressions more difficult to perform, transmit less force to the chest wall and result in less effective resuscitation ${ }^{[5,25-27]}$.

\section{Defibrillation}

With the provision of cardiopulmonary resuscitation (CPR), prompt defibrillation in the setting of ventricular fibrillation or pulseless ventricular tachycardia is critical for successful ROSC and maternal and fetal outcomes ${ }^{[8]}$. Transthoracic impedance remains unchanged during pregnancy, thus the energy requirements and settings should not be altered (i.e., biphasic shock energy of 120 to $200 \mathrm{~J}$, with subsequent energy escalation if first shock is not effective). Moreover, defibrillation is expected to pass minimal energy to the fetus or arcing through fetal monitors; as a consequence, pregnancy or the presence of fetal monitors should not delay intervention ${ }^{[5]}$. In settings of infrequent use or where staff skills of ECG rhythm recognition are limited, the use of an AED should be considered. The lateral pad/paddle should be placed under the breast tissue, and adhesive shock electrodes are recommended to allow consistent defibrillation.

\section{Airway Management}

With pregnancy, patients desaturate more rapidly and have airways that are more difficult to manage. During maternal cardiac arrest, the first responder unfamiliar to airway management should first oxygenate the patient using jaw trust, oral airway and bag-mask ventilation with $100 \%$ oxygen to deliver tidal volume (500-700 mL) over one second for two seconds in total time (Table 1) ${ }^{[4]}$. In the presence of experienced provider, intubation should be attempted, with failure prompting the use of supraglottic airway devices (e.g., laryngeal mask airway). Due to the increased risk of aspiration during pregnancy, oxygenation and ventilation should not be delayed for pharmacologic precautions against aspiration; cricoid pressure can be used initially, unless laryngoscopic visualization is impaired ${ }^{[4]}$.

\section{Intravenous access}

Establishing intravenous (IV) access is essential for 
Table 1. Airway control during maternal cardiac arrest.

\begin{tabular}{ll}
\hline Ventilate with 100\% oxygen & PROVIDE CHEST COMPRESSIONS CONTINUOUSLY \\
\hline Preparation and positioning & $\begin{array}{l}\text { Use jaw thrust + chin lift } \\
\text { Bag mask with } 2 \text { hands + place oral airway if needed } \\
\text { Apply } 30 \text { chest compressions: } 2 \text { breaths per cycle } \\
\text { Give } 2 \text { breaths (each over } 1 \text { second) }\end{array}$ \\
\hline Primary attempt & Call expert airway assistance \\
& Have airway equipment ready (difficult airway cart + portable suction) \\
& Use endotracheal tube (ETT)-consider smallest tube $(6.0$ mm) \\
& Optimize airway position \\
& Continue chest compressions at all times! \\
\hline Secondary attempt & Use Direct or Video laryngoscopy \\
& Apply cricoid pressure \\
& Have a bougie tube immediately available \\
\hline Alternative airway control & Use an alternative laryngoscopy technique \\
& Adjust or release cricoid pressure \\
& Restart mask ventilation if intubation fails \\
& Consider a supraglottic airway (SGA; +/- gastric tube) \\
\hline After airway controlled & Insert SGA (e.g. LMA) \\
& If LMA ventilation is inadequate, return to mask ventilation \\
& If mask ventilation is inadequate- consider cricothyrotomy \\
& First confirm ETT placement \\
& Phen, secure ETT or SGA \\
& Provide 10 breaths/min \\
& Deliver 500-700 mL/breath \\
\hline
\end{tabular}

rapid administration of volume replacement and resuscitation drugs. In the event of difficult IV access, an intraosseous (IO) infusion catheter, preferentially in the proximal humerus (due to being above the diaphragm and higher fluid flow rates than tibial sites) or ultrasound guided peripheral or central access depending on the facility resources should be considered $^{[4]}$.

\section{Drugs used for resuscitation}

Clinicians should be aware of all of the drugs are on the emergency trolley. Altered drug volume of distribution and clearance resulting from physiologic changes of pregnancy are not likely to be relevant in the setting of maternal cardiac arrest. Adrenaline (Epinephrine) $1 \mathrm{mg}$ IV bolus is repeated every 3-5 minutes until ROSC ${ }^{[4]}$.

If cardiac arrest is due to local anesthetic systemic toxicity (LAST), lipid emulsion is administered in the doses used in the non-pregnant population ${ }^{[28]}$. The practice advisory of American Society for Regional Anesthesia (ASRA, 2010) indicates using 20\% lipid emulsion (for a $70-\mathrm{kg}$ adult) as a therapeutic antidote for suspected LAST ${ }^{[29]}$ :
(1) IV bolus $1.5 \mathrm{~mL} \mathrm{~kg}^{-1}$ (lean body mass) over 1 $\min (\approx 100 \mathrm{ml})$

(2) Continuous IV infusion at $0.25 \mathrm{~mL} \mathrm{~kg}^{-1} \mathrm{~min}^{-1}$

(3) Repeat bolus once or twice if persistent cardiovascular collapse

(4) Double the infusion rate to $0.5 \mathrm{~mL} \mathrm{~kg}^{-1} \mathrm{~min}^{-1}$ if blood pressure remains low

(5) Continue infusion for at least $10 \mathrm{~min}$ after attaining circulatory stability

(6) Recommended upper limit: approximately 10 $\mathrm{mL} \mathrm{kg}^{-1}$ lipid emulsion within the first $30 \mathrm{~min}$

Additionally, providers should be familiar with contraindications and side effects of uterotonic drugs (i.e., oxytocin and methylergonovine maleate available in Turkey, carboprost tromethamine). As a systemic vasodilator and negative inotropic agent, oxytocin should not be administered as a rapid (less than $30 \mathrm{sec}$ ), bolus dose more than $5 \mathrm{IU}$ due to the risk of cardiovascular collapse ${ }^{[4]}$. Methylergonovine can cause systemic hypertension, which increases the afterload pressure to the heart. 


\section{Perimortem cesarean or operative vaginal delivery}

Because vaginal delivery is seldom possible in a cardiac arrest situation, perimortem cesarean delivery (PMCD) is a procedure that improves the chance of ROSC and maternal and fetal survival. Teams should continue CPR as they actively prepare to make an incision at 4 minutes following confirmed cardiac arrest, to effect fetal delivery within 5 minutes. Although an operative vaginal delivery is an option, PMCD immediately relieves maternal vena caval obstruction, improves venous return and cardiac output, decreases oxygen demand, and improves pulmonary mechanics ${ }^{[4,30]}$. Moreover, PMCD optimizes neonatal survival (if past the age of viability of 24-25 weeks' gestation) if the fetus is delivered within 5 minutes ${ }^{[5,7,31-33]}$.

The timing of delivery is more critical than the location of delivery. PMCD or operative vaginal delivery should be performed at the site of arrest rather than moving to the nearest operating room [4,34-37]. Patient transport during arrest creates the potential for inadequate chest compressions and delay of definitive care. If PMCD results in ROSC, the parturient can be transported to the nearest $\mathrm{OR}$ after delivery. If ROSC occurs prior to delivery, the parturient can be transported to the OR with the team readily available for immediate cesarean delivery. Subsequently, the mother can be transported to the ICU for postpartum care. While sterile preparation of the skin is not a priority during PMCD, early sterile preparation may be helpful to avoid delays to incision ${ }^{[4]}$.

\section{Postcardiac arrest care}

In parturients who are refractory to CPR after PMCD, the use of mechanical circulatory support [i.e., extracorporeal membrane oxygenation (ECMO)] can be considered if available ${ }^{[38,39]}$. Therapeutic hypothermia has been used safely and effectively in early pregnancy with favorable maternal and fetal outcome after term delivery ${ }^{[40]}$. Implantable cardioverter defibrillators (ICDs) have been used successfully during pregnancy ${ }^{[41]}$. Due to the many possible causes of maternal cardiac arrest (Figure 1), maternal transfer to an ICU should occur promptly to continue patient treatment and stabilization ${ }^{[4]}$.
In conclusion, the main priority in the management of maternal cardiac arrest is resuscitating the mother with a good teamwork. Initiating rapid and forceful cardiac compressions, defibrillating appropriate rhythms, mitigating aortocaval compression, managing the airway, and quickly initiating a perimortem delivery are key interventions that augment maternal and fetal survival in this difficult setting.

We, the authors, declare that we do not have any conflicts of interest regarding our paper entitled "Management of cardiac arrest in pregnancy" which has been submitted to Journal of The Society of Thoracic Cardio-Vascular Anaesthesia and Intensive Care.

\section{REFERENCES}

1. http://data.worldbank .org/indicator/SH.STA.MMRT MMR modeled estimate, per 100,000 live births from WHO, UNICEF, UNFPA, World Bank Group, and the United Nations Population Division. Trends in Maternal Mortality: 1990 to 2015. Geneva, World Health Organization, 2015.

2. Soar J, Perkins GD, Abbas G, Alfonzo A, Barelli A, Bierens JJLM et al. European Resuscitation Council Guidelines for Resuscitation 2010 Section 8. Cardiac arrest in special circumstances: Electrolyte abnormalities, poisoning, drowning, accidental hypothermia, hyperthermia, asthma, anaphylaxis, cardiac surgery, trauma, pregnancy, electrocution. Resuscitation 2010;81:140033.

https:/doi.org/10.1016/j.resuscitation.2010.08.015

3. American Society of Anesthesiology (ASA) Standards, Guidelines, and Statements American Society of Anesthesiology 2013. Available at: http://www.asahq.org/ For-Members/ Standards-Guidelines-and-Statements. aspx Accessed March 23, 2014

4. Lipman S, Cohen S, Einav S, Jeejeebhoy F, Mhyre JM, Morrison LJ, et al. The society for obstetric anesthesia and perinatology consensus statement on the management of cardiac arrest in pregnancy. Anesth Analg 2014;118:1003-16. https:/doi.org/10.1213/ANE.0000000000000171

5. Jeejeebhoy FM, Zelop CM, Lipman S, Carvalho B, Joglar J, Mhyre JM, et al. American Heart Association Emergency Cardiovascular Care Committee, Council on Cardiopulmonary, Critical Care, Perioperative and Resuscitation, Council on Cardiovascular Diseases in the Young, and Council on Clinical Cardiology. Cardiac Arrest in Pregnancy: A Scientific Statement From the American Heart Association. Circulation 2015;132 (18):1747-73 https:/doi.org/10.1161/CIR.0000000000000300

6. Lipman SS, Daniels KI, Carvalho B, Arafeh J, Harney K, Puck A, et al. Deficits in the provision of cardiopulmonary resuscitation during simulated obstetric crises. Am J Obstet Gynecol 2010;203:179.e1-5. https:/doi.org/10.1016/j.ajog.2010.02.022

7. Hui D, Morrison LJ, Windrim R, Lausman AY, 
Hawryluck L, Dorian P, et al. The American Heart Association 2010 guidelines for the management of cardiac arrest in pregnancy: consensus recommendations on implementation strategies. J Obstet Gynaecol Can 2011;33:858-63

https:/doi.org/10.1016/S1701-2163(16)34991-X

8. Neumar RW, Otto CW, Link MS, Kronick SL, Shuster M, Callaway CW, et al. Part 8: Adult advanced cardiovascular life support: 2010 American Heart Association Guidelines for Cardiopulmonary Resuscitation and Emergency Cardiovascular Care. Circulation 2010;122:S729-67.

https:/doi.org/10.1161/CIRCULATIONAHA.110.970988

9. Cheskes S, Schmicker RH, Christenson J, Salcido DD, Rea T, Powell J, et al. Resuscitation Outcomes Consortium (ROC) Investigators. Perishock pause: an independent predictor of survival from out-of-hospital shockable cardiac arrest. Circulation 2011;124:58-66. https:/doi.org/10.1161/CIRCULATIONAHA.110.010736

10. Hightower D, Thomas SH, Stone CK, Dunn K, March JA. Decay in quality of closed-chest compressions over time. Ann Emerg Med 1995;26:300-3. https:/doi.org/10.1016/S0196-0644(95)70076-5

11. Sugerman NT, Edelson DP, Leary M, Weidman EK, Herzberg DL, Vanden Hoek TL, et al. Rescuer fatigue during actual in-hospital cardiopulmonary resuscitation with audiovisual feedback: a prospective multicenter study. Resuscitation 2009;80:981-4. https:/doi.org/10.1016/j.resuscitation.2009.06.002

12. McDonald CH, Heggie J, Jones CM, Thorne CJ, Hulme J. Rescuer fatigue under the 2010 ERC guidelines, and its effect on cardiopulmonary resuscitation (CPR) performance. Emerg Med J 2013;30:623-7. https:/doi.org/10.1136/emermed-2012-201610

13. Pernat A, Weil MH, Sun S, Tang W. Stroke volumes and end- tidal carbon dioxide generated by precordial compression during ventricular fibrillation. Crit Care Med 2003;31:1819-23. https:/doi.org/10.1097/01.CCM.0000069538.12447.82

14. Wayne MA, Levine RL, Miller CC. Use of end-tidal carbon dioxide to predict outcome in prehospital cardiac arrest. Ann Emerg Med 1995;25:762-7. https:/doi.org/10.1016/S0196-0644(95)70204-0

15. Eckstein M, Hatch L, Malleck J, McClung C, Henderson SO. End-tidal $\mathrm{CO}_{2}$ as a predictor of survival in out-of-hospital cardiac arrest. Prehosp Disaster Med 2011;26:148-50. https:/doi.org/10.1017/S1049023X11006376

16. Einav S, Bromiker R, Weiniger CF, Matot I. Mathematical modeling for prediction of survival from resuscitation based on computerized continuous capnography: proof of concept. Acad Emerg Med 2011;18:468-75. https:/doi.org/10.1111/j.1553-2712.2011.01067.x

17. Kolar M, Krizmaric M, Klemen P, Grmec S. Partial pressure of end-tidal carbon dioxide successful predicts cardiopulmonary resuscitation in the field: a prospective observational study. Crit Care 2008;12:R115. https:/doi.org/10.1186/cc7009

18. Pokorná M, Necas E, Kratochvíl J, Skripskı R, Andrlík M, Franek O. A sudden increase in partial pressure end-tidal carbon dioxide $\left(\mathrm{P}(\mathrm{ET}) \mathrm{CO}\left({ }_{2}\right)\right)$ at the moment of return of spontaneous circulation.J Emerg Med 2010;38:614-21.

https:/doi.org/10.1016/j.jemermed.2009.04.064
19. McLennan C, Minn M. Antecubital and femoral venous pressure in normal and toxemic pregnancy. Am J Obstet Gynecol 1943;45:568-91. https:/doi.org/10.1016/S0002-9378(43)90832-4

20. Ueland K, Novy MJ, Peterson EN, Metcalfe J. Maternal cardiovascular dynamics. IV. The influence of gestational age on the maternal cardiovascular response to posture and exercise. Am J Obstet Gynecol 1969;104:856-6. https:/doi.org/10.1016/0002-9378(69)90637-1

21. McLennan CE. Antecubital and femoral venous pressure in normal and toxemic pregnancy. Am J Obstet Gynecol 1943;45:568. https:/doi.org/10.1016/S0002-9378(43)90832-4

22. Noordergraaf GJ, Paulussen IW, Venema A, van Berkom PF, Woerlee PH, Scheffer GJ, et al. The impact of compliant surfaces on in-hospital chest compressions: effects of common mattresses and a backboard. Resuscitation 2009;80:546-52.

https:/doi.org/10.1016/j.resuscitation.2009.03.023

23. Nishisaki A, Maltese MR, Niles DE, Sutton RM, Urbano J, Berg RA, et al. Backboards are important when chest compressions are provided on a soft mattress. Resuscitation 2012;83:1013-20. https:/doi.org/10.1016/j.resuscitation.2012.01.016

24. Kundra P, Khanna S, Habeebullah S, Ravishankar M. Manual displacement of the uterus during caesarean section. Anaesthesia 2007;62:460-5. https:/doi.org/10.1111/j.1365-2044.2007.05025.x

25. Jeejeebhoy FM, Zelop CM, Windrim R, Carvalho JC, Dorian P, Morrison LJ. Management of cardiac arrest in pregnancy: a systematic review. Resuscitation 2011;82:801-9. https:/doi.org/10.1016/j.resuscitation.2011.01.028

26. Rees GA, Willis BA. Resuscitation in late pregnancy. Anesthesia 1988;43:347-9. https:/doi.org/10.1111/j.1365-2044.1988.tb09009.x

27. Suresh MS, LaToya Mason C, Munnur U. Cardiopulmonary resuscitation and the parturient. Best Pract Res Clin Obstet Gynaecol 2010;24:383-400. https:/doi.org/10.1016/j.bpobgyn.2010.01.002

28. Bern S, Weinberg G. Local anesthetic toxicity and lipid resuscitation in pregnancy. Curr Opin Anesthesiol 2011; 24:262-7. https:/doi.org/10.1097/ACO.0b013e32834654df

29. Neal JM, Bernards CM, Butterworth JF 4th, Di Gregorio G, Draner K, Heitmanek MR, et al. The American Society of Regional Anesthesia and Pain Medicine Practice Advisory on Local Anesthetic Systemic Toxicity assimilates and summarizes current knowledge regarding the prevention, diagnosis, and treatment of this potentially fatal complication. Reg Anesth Pain Med 2010; 35:152-61. https:/doi.org/10.1097/AAP.0b013e3181d22fcd

30. Johnston D. Maternal collapse and perimortem caesarean section. WFSA's Update in Anaesthesia 2007; 23:11-3.

31. Katz VL, Dotters DJ, Droegemueller W. Perimortem cesarean delivery. Obstet Gynecol 1986;68:571-6.

32. Katz V, Balderston $K$, DeFreest $M$. Perimortem cesarean delivery: were our assumptions correct? Am J Obstet Gynecol 2005;192:1916-21. https:/doi.org/10.1016/j.ajog.2005.02.038

33. Katz VL. Perimortem cesarean delivery: its role in ma- 
ternal mortality. Semin Perinatol 2012;36:68-72. https:/doi.org/10.1053/j.semperi.2011.09.013

34. Lipman S, Daniels K, Cohen SE, Carvalho B. Labor room setting compared with the operating room for simulated perimortem cesarean delivery: a randomized controlled trial. Obstet Gynecol 2011;118:1090-4. https:/doi.org/10.1097/AOG.0b013e3182319a08

35. Clark SL, Hankins GD, Dudley DA, Dildy GA, Porter TF. Amniotic fluid embolism: analysis of the national registry. Am J Obstet Gynecol 1995;172:115869.

https:/doi.org/10.1016/0002-9378(95)91474-9

36. Lofsky A. Doctors company reviews maternal arrests cases. Anesth Patient Saf Found Newsl 2007;22:28-30.

37. Lipman SS, Wong JY, Arafeh J, Cohen SE, Carvalho B. Transport decreases the quality of cardiopulmonary resuscitation during simulated maternal cardiac arrest. Anesth Analg 2013;116:162-7. https:/doi.org/10.1213/ANE.0b013e31826dd889
38. Shen HP, Chang WC, Yeh LS, Ho M. Amniotic fluid embolism treated with emergency extracorporeal membrane oxygenation: a case report. J Reprod Med 2009;54:706-8.

39. Ecker JL, Solt K, Fitzsimons MG, MacGillivray TE. Case records of the Massachusetts General Hospital. Case 40-2012. A year-old woman with cardiorespiratory arrest after a cesarean section. $N$ Engl $\mathrm{J} \mathrm{Med}$ 2012;367:2528-36. https:/doi.org/10.1056/NEJMcpc1201413

40. Rittenberger JC, Kelly E, Jang D, Greer K, Heffner A. Successful outcome utilizing hyothermia after cardaic arrest in pregnancy: a case report. Crit Care Med 2008;36:1354-6.

https:/doi.org/10.1097/CCM.0b013e318169ee99

41. Natale A, Davidson T, Geiger MJ, Newby K. Implantable cardioverter dfibrillators and pregnancy: a safe combination? Circulation 1997;96:2808-12. https:/doi.org/10.1161/01.CIR.96.9.2808 